\title{
Pengembangan Game Puzzle Sebagai Edugame Berbasis Android Untuk Meningkatkan Kemampuan Berpikir Matematika Siswa SD
}

\author{
${ }^{1}$ Baiq Olatul Aini, ${ }^{2}$ Khaerunnisa Cantika Ayu, ${ }^{3}$ Siswati \\ ${ }^{1,2,3}$ Tadris Matematika, Universitas Islam Negeri Mataram, Indonesia \\ 17170103015.mhs@uinmataram.ac.id, ${ }^{2}$ 170103016.mhs@uinmataram.ac.id, ${ }^{3}$ 170103017.mhs@uinmataram.ac.id
}

\section{INFO ARTIKEL}

RiwayatArtikel:

Diterima: 03-03-2019

Disetujui: 30-04-2019

\section{Kata Kunci: \\ Game Puzzle; \\ Geometri; \\ Aljabar ; \\ Apps Geyser.}

Edugame;

\section{Keywords: \\ Game Puzzle; \\ Edugame; \\ Geometry;}

Algebra;

\section{ABSTRAK}

Abstrak: Pada aplikasi game puzzle ini berisi materi teori bilangan, aljabar, bangun datar dan bangun ruang. Pada game ini terdapat 15 level dan dibuat dari Appsgeyser. Penelitian ini bertujuan untuk meningkatkan kemampuan berpikir melalui minat belajar siswa di SD kelas III, IV, V dan VI. Dampak dari media pembelajaran edugame ini adalah media pembelajaran berpengaruh pada kemampuan berpikir siswa. Instrument penelitian yang digunakan adalah pedoman angket dan observasi. Berdasarkan hasil analisis data, diperoleh hasil validasi dari ahli media dengan skor rata-rata $73,649 \%$ dalam kriteria layak, sedangkan respon dari pengguna rata-rata sebesar $80,335 \%$ dalam kreteria menarik.

Abstract: In this puzzle game application contains material in number theory, algebra, wake up flat and build space. In this game there are 15 levels and are made from Appsgeyser. This study aims to increase students' interest in learning at SD class III, $I V, V$, and VI. The impact of edugame learning media is learning media influencing student learning outcomes. The research instrument used was the questionnaire and observation guidelines. Based on the results of data analysis, the results of validation from media experts were obtained with an average score of 73,649\% in eligible criteria, while the response from users on average was $80,335 \%$ in the criteria interesting.
\end{abstract}

Apps Geyser.

\section{A. LATAR BELAKANG}

Pendidikan sangat penting untuk mengembangkan potensi diri untuk terciptanya kehidupan yang lebih berkualitas dan kreatifitas. Menurut Undang-undang No. 20 tahun 2003 pasal 1 dalam Permendikbud No. 65 tahun 2013 menerangkan bahwa pendidikan adalah usaha sadar dan terencana untuk mewujudkan suasana belajar dan proses pembelajaran agar peserta didik secara aktif mengembangkan potensi dirinya untuk memiliki kekuatan spiritual keagamaan, pengendalian diri, kepribadian, kecerdasan, akhlak mulia, serta keterampilan yang diperlukan dirinya, masyarakat, bangsa dan negara. Pemerintah mengharapkan adanya perubahan yang positif dalam meningkatkan pendidikan Indonesia. Salah satunya tuntutan pemerintah yang harus diterapkan dalam pembelajaran adalah mengembangkan perangkat pembelajaran berbasis android untuk meningkatkan kemampuan berpikir siswa SD.

Berdasarkan tuntutan pemerintah untuk meningkatkan mutu pendidikan Indonesia salah satunya pembelajaran matematika, maka perlu dilakukan inovasi dalam proses pembelajaran yaitu dengan menerapkan model pembelajaran dan pemilihan media pembelajaran yang tepat. Pembelajaran yang inovatif bertujuan untuk 
merangsang minat, keaktifan, kreatifitas dan peningkatan hasil kemampuan berpikir peserta didik (Rizki, 2018 : 88)

Matematika adalah study besaran, struktur, ruang dan perubahan. Matematika paling banyak digunakan untuk menghitung berbagai nilai besaran. Matematika akan lebih mudah diajarkan pada anak sejak usia dini, anak-anak akan lebih mudah mengingat dalam belajar mengingat simbol, lambang dan menghitung. Untuk daya tangkap pembelajaran yang baik pada saat ini atau sebelumnya lebih ditekankan kepada pendidikkan visual yang terlihat menarik dengan tambahan gambar dan suara.

Kemajuan ilmu pengetahuan dan teknologi memiliki pengaruh yang sangat besar dalam berbagai bidang kehidupan manusia. Pendidikan sebagai salah satu bagian yang tidak terpisahkan dari proses pendewasaan manusia tentu di satu sisi memiliki andil yang besar bagi pengembangan ilmu pengetahuan dan teknologi tersebut. Namun, di sisi lain pendidikan juga perlu memanfaatkan kemajuan ilmu pengetahuan dan teknologi agar mampu mencapai tujuannya secara efektif dan efisien. Kemajuan ilmu pengetahuan dan teknologi telah berpengaruh terhadap penggunaan alat-alat bantu mengajar di sekolah-sekolah dan lembaga-lembaga pendidikan lainnya.

Perkembangan teknologi perangkat komputer serta aplikasi di segala bidang menuntut banyak pihak memberikan perhatian khusus kepadanya. Penguasaan terhadap teknologi tersebut merupakan satu hal yang perlu dimiliki generasi muda pada masa sekarang ini (Setiani, 2014).

Tuntutan era globalisasi dengan perkembangan teknologi informasi dapat dimanfaatkan untuk pengembangan pembelajaran (Tanrere, 2012; Akhmadan, 2017). Salah satu cara penggunaan teknologi yang baik yaitu memanfaatkan sumber teknologi sebagai media dalam proses pembelajaran (Akhmadan, 2017).

Berkembangnya ilmu pengetahuan dan teknologi berpengaruh dan membawa perubahan pada dunia pendidikan. Pendidikan berperan penting dalam peningkatan kualitas sumber daya manusia, sehingga perlu dilakukan upaya perbaikan dan peningkatan kualitas pada bidang pendidikan tersebut (Margarita, 2014; Rusnilawati, 2016; Harta, 2017).
Di sisi lain, media pembelajaran komputer belum dimanfaatkan secara optimal di dalam proses belajar mengajar. Berdasarkan hasil observasi dan wawancara yang dilakukan di salah satu SD, menunjukkan bahwa penggunaan media pembelajaran menggunakan andoid belum dimanfaatkan sebagai media pembelajaran, termasuk pada pelajaran matematika. Selain itu, guru menyampaikan pembelajaran seperti biasa dan tidak menggunakan media pembelajaran seperti game matematika, sehingga siswa kurang tertarik dan kurang bersemangat dalam mengikuti pelajaran matematika.

Berdasarkan uraian tersebut, perlu adanya pengembangan media pembelajaran android salah satunya yaitu dengan membuat aplikasi permainan yang dapat gunakan melalui computer atau android. Aplikasi pembuat game atau biasa disebut game engine sudah beragam salah satunya adalah dengan menggunakan AppsGeyser.

Menurut Schramm, media pembelajaran merupakan teknologi pembawa pesan yang dapat dimanpaatkan untuk keperluan pembelajaran (dalam Titon Agung Saputro,Kriswandani,Novisita Ratu, 2018:21)

Multimedia pembelajaran berupa game berguna dalam mendukung kegiatan belajar mengajar, tetapi belum banyak game yang dibuat untuk fungsi pembelajaran disekolah. Akhirnya game mulai dimanfaatkan sebagai salah satu media pembelajaran dengan harapan siswa menjadi lebih tertarik dan menghabiskan lebih banyak waktu untuk belajar. Fenomena yang terjadi adalah anakanak sering melupakan belajar karena waktu yang seharusnya untuk belajar dihabisakan dengan bermain game. Alangkah baiknya game yang dibuat dan dimainkan anak-anak adalah game yang dimanfaatkan di dunia pendidikan guna mendukung kegiatan belajar mengajar dan menarik minat motivasi belajar siswa.

\section{B. METODE PENELITIAN}

\section{Jenis Penelitian}

Jenis penelitan ini merupkan penelitian pengembangan (Research and Development/ $R \& D$ ). Penelitian pengembangan ini adalah untuk menghasilkan produk terbaru. Pendapat lain mengatakan bahwa penelitian pengembangan adalah suatu proses yang digunakan untuk 
mengembangkan dan menvalidasi produk-produk yang digunakan dalam pendidikan dan pembelajaran. Model pengembangan software yang digunakan dalam penelitian ini adalah 4-D (Define, Design, Develop, and Disemination) yang dikembangkan oleh Thiagarajan, Semmel dan Semmel yang dimodifikasi (Syaharuddin, 2015: 185).

\section{Responden Penelitian}

Uji coba dilakukan setelah melakukan validasi tiga (3) tim pakar yakni pakar media, pakar desain, dan pakar komputasi. Sedangkan uji coba lapangan dilakukan pada 8 siswa Sekolah Dasar yang diambil dari kelas III, IV, V, dan VI.

\section{Prosedur Penelitan}

Adapun prosedur penelitian ini sesuai Gambar 1 berikut ini.

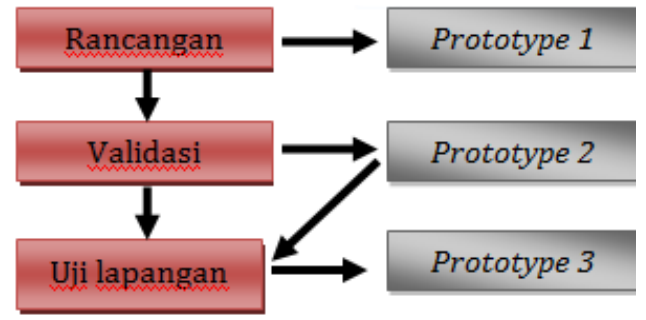

Gambar 1. Langkah Kegiatan Revisi Produk (software)

\section{Teknik Analisis Data}

Menurut Muliyardi (dalam Syharuddin, 2018 : 187) Proses analisis data validitas software yang dikembangkan di lakukan dengan rumus sebagai berikut :

$$
R=\frac{\sum_{i=1}^{n} V_{i}}{n}
$$

Keterangan :

$\mathrm{R}=$ rerata hasil penelitian dari para validator

$\mathrm{V}_{\mathrm{i}}=$ skor hasil penelitian validator ke- $\mathrm{i}$

$\mathrm{n}=$ banyak validator

Hasil tabulasi tiap respon dicari presentasenya, dengan rumus :

$$
p=\sum \frac{\text { skor peritem }}{\text { skormak }} \times 100 \%
$$

Tabel 1. Interval Nilai Validasi Program

\begin{tabular}{cl}
\hline Interval Nilai & \multicolumn{1}{c}{ Kategori } \\
\hline $\mathrm{R}=5$ & Sangat valid/baik \\
\hline $4 \leq \mathrm{R}<5$ & Valid/baik \\
\hline $3 \leq \mathrm{R}<4$ & Cukup valid/baik \\
\hline
\end{tabular}

\begin{tabular}{cl}
\hline $2 \leq \mathrm{R}<3$ & Kurang valid/baik \\
\hline $1 \leq \mathrm{R}<2$ & Sangat kurang valid/baik \\
\hline
\end{tabular}

Sedangkan untuk hasil uji coba lapangan menggunakan interval penilaian berikut.

\begin{tabular}{cc}
\multicolumn{2}{c}{ Tabel 2. Interval Kategori Program (\%) } \\
\hline Persentase (\%) & Kategori \\
$0-20$ & Tidak baik \\
$21-40$ & Kurang baik \\
$41-60$ & Cukup baik \\
$61-80$ & Baik \\
$81-100$ & Sangat baik \\
\hline
\end{tabular}

\section{HASIL DAN PEMBAHASAN}

Puzzle game merupakan jenis game yang menekankan pemecahan teka-teki. Jenis teka-teki yang harus dipecahkan dapat menguji kemampuan memecahkan banyak masalah termaksud logika, strategi, dan pengenalan pola. Penelitian dengan mengembangkan aplikasi Appgeyser sebelumnya pernah juga dilakukan, penelitian dan pengembangan yang dilakukan hanya memindahkan materi kedalam media yang disertai dengan tomboltombol yang berfungsi untuk menghubungkan slide yang diinginkan oleh pemakai terlihat dalam tampilan hasil media pembelajaran. Pada pengembangan ini diberi beberapa gambar sebagai acuan sebagai rangsangan motivasi siswa untuk mempelajari materi dan diberi simulasi-simulasi yang berkaitan dengan kehidupan sehari-hari yang diharapkan bisa merangsang cara berfikir siswa, data potensi dan masalah, maka peneliti melakukan observasi dengan menyebarkan angket. Angket yang dimaksud berupa sederetan 24 pertanyaan yang menjawabnya disertai alasan dan sebelum disebar terlebih dahulu divalidasi oleh Dosen UIN Mataram.

\section{Desain Game Puzzle}

Setelah diperoleh data informasi dari study lapangan dan study literatur, maka dapat digunakan sebagai bahan rujukan untuk perencanaan pengembangan produk yang telah dibuat. Data informasi yang terkumpul dijadikan sebagai bahan pertimbangan untuk analisis sumber kebutuhan belajar baru berupa modul yang akan dikembangkan. Setelah analisis kebutuhan, diketahui sekiranya mengenai rancangan produk yang akan dikembangkan. Selanjutnya tahap pembuatan media. Media dibuat dengan menggunakan progam aplikasi Appsgeyser. 


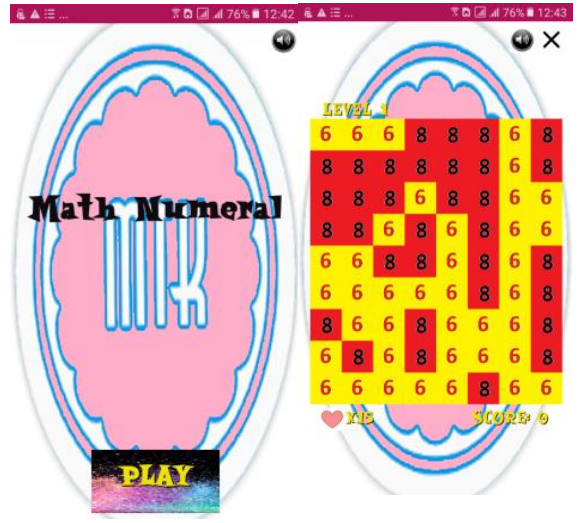

Gambar 2. Tampilan Aplikasi Puzzle Materi Teori Bilangan.
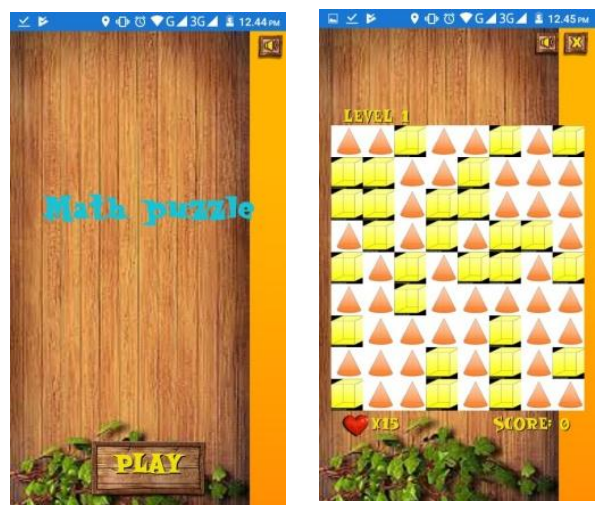

Gambar 3. Tampilan Aplikasi Puzzle Materi Geometri

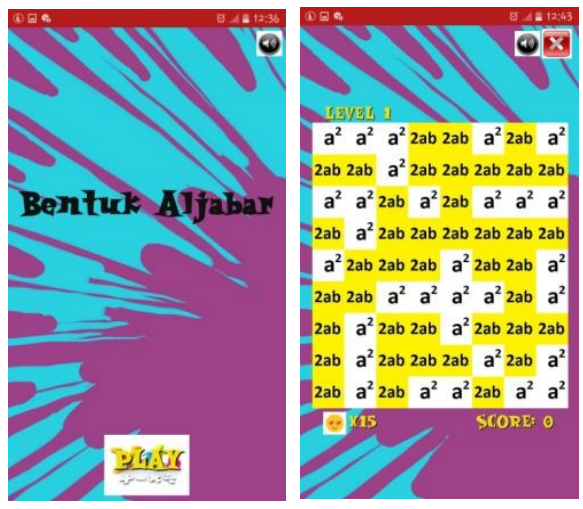

Gambar 4. Tampilan Aplikasi Puzzle Materi Aljabar

\section{Hasil Validasi Ahli}

Validasi desain merupakan langkah untuk menilai apakah rancangan pengembangan produk yang dibuat layak atau tidaknya dipakai di Sekolah Dasar. Setelah desain produk selesai, kemudian dilakukan penilaian oleh para ahli media. Dari masing-masing penilaian yang diberikan oleh validator media pembelajaran yang dikembangkan dinyatakan layak dan menarik digunakan sebagai media pembelajaran setelah dilakukan revisi. Untuk hasil validasi dari validator sebagaimana pada tabel dibawah.
Tabel 3. Hasil Validasi Ahli Media Teori Bilangan

\begin{tabular}{ccc}
\hline Nama & Rata-rata & Persentase(\%) \\
\hline Validator 1 & 2,857 & $57,142 \%$ \\
\hline Validator 2 & 3,857 & $77,142 \%$ \\
\hline Validator 3 & 4,285 & $85,714 \%$ \\
\hline
\end{tabular}

Tabel 4. Hasil Validasi Ahli Media Geometri

\begin{tabular}{ccc}
\hline Nama & Rata-rata & Persentase (\%) \\
\hline Validator 1 & 2,714 & $54,28 \%$ \\
\hline Validator 2 & 3,857 & $77,142 \%$ \\
\hline Validator 3 & 4 & $80 \%$ \\
\hline
\end{tabular}

Tabel 5. Hasil Validasi Ahli Media Aljabar

\begin{tabular}{ccc}
\hline Nama & Rata-rata & Persentase (\%) \\
\hline Validator 1 & 3,714 & $74,285 \%$ \\
\hline Validator 2 & 3,857 & $77,142 \%$ \\
\hline Validator 3 & 4 & $80 \%$ \\
\hline
\end{tabular}

\section{Hasil Uji Coba Lapangan}

Setelah dilakukan validasi oleh ahli dan dikatakan layak, maka dilakukan uji coba pengguna dan di dapat hasil sesuai Tabel 6, Tabel 7 dan Tabel 8 sebagai berikut:

Tabel 6. Hasil Uji Coba Pengguna Teori Bilangan

\begin{tabular}{cccc}
\hline Nama & Kelas & Rata-rata & Persentase (\%) \\
\hline Responden 1 & IV & 4,0833 & $82,5 \%$ \\
\hline Responden 2 & V & 4,1667 & $83,33 \%$ \\
\hline Responden 3 & VI & 4,458 & $89,1667 \%$ \\
\hline Responden 4 & VI & 4,33 & $86,667 \%$ \\
\hline Responden 5 & V & 4,25 & $85 \%$ \\
\hline Responden 6 & V & 4,0833 & $81,667 \%$ \\
\hline Responden 7 & III & 4,125 & $8,25 \%$ \\
\hline Responden 8 & III & 4,1667 & $83,33 \%$ \\
\hline
\end{tabular}

Tabel 7. Hasil Uji Coba Pengguna Geometri

\begin{tabular}{cccc}
\hline Nama & Kelas & Rata-rata & Persentase (\%) \\
\hline Responden 1 & IV & 4,0833 & $81,667 \%$ \\
\hline Responden 2 & V & 4,125 & $82,5 \%$ \\
\hline Responden 3 & VI & 4,458 & $89,167 \%$ \\
\hline Responden 4 & VI & 4,2917 & $85,83 \%$ \\
\hline Responden 5 & V & 4,1667 & $83,33 \%$ \\
\hline Responden 6 & V & 4,333 & $86,667 \%$ \\
\hline Responden 7 & III & 4,125 & $82,5 \%$ \\
\hline Responden 8 & III & 4,0416 & $80,833 \%$ \\
\hline
\end{tabular}

Tabel 8. Hasil Uji Coba Pengguna Aljabar

\begin{tabular}{cccc}
\hline Nama & Kelas & Rata-rata & Persentase (\%) \\
\hline Responden 1 & IV & 4,297 & $85,83 \%$ \\
\hline Responden 2 & V & 4,375 & $87,5 \%$ \\
\hline Responden 3 & VI & 4,458 & $89,1667 \%$ \\
\hline Responden 4 & VI & 4,125 & $82,5 \%$ \\
\hline Responden 5 & V & 4,1667 & $83,33 \%$ \\
\hline Responden 6 & V & 4 & $80 \%$ \\
\hline Responden 7 & III & 4,0833 & $81,667 \%$ \\
\hline Responden 8 & III & 4,0833 & $81,667 \%$ \\
\hline
\end{tabular}




\section{Respon Ahli Media dan Pengguna}

Berdasarkan hasil validasi ahli diperoleh respon dari ahli meliputi (1) Tata letak input, output, tombol dan sejenisnya sudah sesuai (2) Keteraturan dan konsistensi tampilan tombol sudah sesuai (3) Kesesuaian pemilihan icon dan jenis huruf sudah pas. Sedangkan masukan dari ahli yakni warna background seharusnya lebih teran pada android. Permainan ini bermanfaat bagi pembelajaran matematika di tingkat SD, permainannya jua jua sangat menarik karena mudah dimainkan oleh siswa SD dengan masing-masing materi dicocokkan dikelas yang berbeda, misalkan pada teori bilangan: usahakan dimainkan oleh siswa kelas 3 SD karena diaplikasi tersebut mengenalkan angka dan bilangan sederhana, sedangkan materi geometri yaitu bangun ruang dan bangun datar lebih cocok untuk dimainkan oleh kelas $4 \mathrm{SD}$, dan begitu juga dengan materi aljabar cocok digunakan di kelas 5 dan 6 SD.

Kemudian respon dari siswa sebagai pengguna yakni Game ini sangat menarik karena selain mengenalkan pembelajaran matematika dasar, permainan tersebut juga mudah dipahami cara penggunaannya. Dari ketiga aplikasi tersebut, dalam percobaan pertama yang paling sulit dimainkan adalah geometri yaitu, menentukan bangun ruang dan bangun datar yang sejenis, dan yang paling cepat adalah aljabar.

Di samping itu, terlihat para siswa sangat antusias dalam mengoperasikan media pembelajaran yang tim sosialisasikan. Hal ini karena penyampaian game ini dikolaborasikan dengan permainan di kelas sehingga siswa sangat menikmati pembelajaran di kelas.

\section{SIMPULAN DAN SARAN}

Berdasarkan hasil validasi terhadap pengembangan media pembelajaran matematika dengan menggunakan program AppsGeyser diperoleh skor di atas 70,00; (1) kelayakan pengembangan media pembelajaran matematika dengan menggunakan program aplikasi AppsGeyser hasil validasi dari ahli media diperoleh rata-rata dari hasil ketiga aplikasi game yang dibuat yaitu teori bilangan, geometri, dan aljabar adalah 73,649\%. Produk hasil validasi adalah dalam kriteria "menarik", (2) kemenarikan pengembangan media pembelajaran matematika dengan menggunakan program AppsGeyser respon siswa dari hasil ketiga aplikasi game yang dibuat yaitu teori bilangan, geometri, dan aljabar diperoleh skor rata-rata $80,333 \%$ dalam kriteria "sangat menarik".

Adapun saran untuk penelitian dan pengembangan ini masih memerlukan tindak lanjut sampai pada keefektifan agar diperoleh produk media pembelajaran yang lebih berkualitas dan dapat digunakan dalam pembelajaran. Semoga penelitian ini dapat bermanfaat dan menjadi sumber rujukan ataupun referensi penelitian selanjutnya.

\section{REFERENSI}

Agung Titon Saputro, Kriswardari, Ratu Novisita. (2018). Pengembangan Media Pembelajaran Menggunakan Aplikasi Construct 2 Pada Materi Aljabar Kelas VII. Jurnal Dan Aplikasi Matematika, 2(1), 1-8

Faiq, Ahmad Abror. (2012). Mathematics Adventure Games Berbasis Role Playing Game (RPG) Sebagai Media Pembelajaran Mata Pelajaran Matematika Kelas VI SD Negeri Jetis 1. eprints.uny.ac.id

Falahudin, Iwan. (2014). Pemanfaatan Media Dalam Pembelajaran. Jurnal Lingkar Widyaiswara, 1(4). 104117.

Harlinda Riski Putri, Hardjono Nyotu. (2018). Peningkatan Hasil Belajar Tematik Melalui Penerapan Model Problem Based Learning Dengan Media Mind Mapping. Jurnal Riset Teknologi Dan Inovasi Pendidikan, 2(1), 87-101

Husein, Hamdan Batubara.(2017). Pengembangan Media Pembelajaran Matematika Berbasis Android Untuk Siswa SD/MI. MUALLIMUNA: Jurnal Madrasah Ibtidaiyah, 3(1), 12-27.

Kholiqul, Ahmad Amin., dan Mayasari,Novi. (2015) Pengembangan Media Pembelajaran Berbentuk Aplikasi Android Berbasis Weblog Untuk Meningkatkan Hasil Belajar Mahasiswa Pendidikan Matematika Ikip PGRI Bojonegoro. Pengembangan Media Pembelajaran Berbentuk Aplikasi Android Berbasis Weblog. (94), 12-23.

Masykur, R., Nofrizal, Syazali, M. (2017). Pengebangan Media Pembelajaran Matematika Dengan Marcomedia Flash. Al-Jabar : Jurnal Pendidikan Matematika, 8(2), 178-186

Muliyardi. (2006). Pengenbangan Model Pembelajaran Matematika Menggunakan Komik Dikelas 1 Sekolah Dasar. Disertasi, UNESA, Surabaya

Purwanti, Ika. (2013). Perancangan Aplikasi Pembelajaran Huruf Hijaiyah Berplatform Android Untuk Madrasah Baca Tulis Al Quran Al-Fattah Desa Widodaren Kabupaten Ngawi. Seminar Riset Unggulan Nasional Informatika dan Komputer FTI UNSA, 2(1), 123-130

Rohana. (2015). Peningkatan Kemampuan Penalaran Matematis Mahasiswa Calon Guru Melalui Pembelajaran Reflektif. Ilmiah Program Studi Matematik STKIP Siliwangi Bandung, 4(1), 105-118

Suhendar, Rizki Putra, Wijayati, Nanik., dan Mahatmanti, Widhi. (2017). Pengaruh Pengunaan Media Pembelajaran Berbasis Aplikasi Android Terhadap Hasil Belajar Siswa . Inovasi Pendidikan Kimia, 11(2), 2008-2018 
Syaharuddin. Mandailina, Vera,. and Septiana, Yunita anwar.

(2015). Pengembangan Software Matematika Smp/Mts Berbasis Solutif Menggunakan Borland Delphi. Beta, 8 (2), 183-192.

Syaharuddin. Mandailina, Vera. (2017). Pengembangan Modul Pemrograman Komputer Berbasis Matlab. Jurnal Teori dan Aplikasi Matematika, 1(1), 01-04 